\title{
Uma leitura benjaminiana do tempo em Dom Casmurro e Capitu.
}

\section{Lara Luiza Spagnol Oliveira, UFMG}

Resumo: O presente artigo objetiva realizar aproximações entre a concepção temporal de Walter Benjamin - especificamente no que diz respeito às suas Teses Sobre o Conceito de História - e as obras Dom Casmurro, de Machado de Assis, e sua adaptação televisiva, a microssérie Capitu, dirigida por Luiz Fernando Carvalho. Almejamos compreender, especificamente, de que maneiras o tempo que percorre tais obras está próximo da imagem de um tempo constelar, múltiplo, não-linear e heterogêneo, tal qual conceituado por Benjamin.

Palavras-chave: tempo; memória; tradução intersemiótica.

Se existe uma suposta cisão entre o campo da literatura e o campo da filosofia, é inegável que também existam inúmeros pontos de encontro capazes de conectar essas duas instâncias. A leitura de alguns expoentes da obra do filósofo alemão Walter Benjamin parece desvelar, justamente, um pensamento que passeia por estes entrelugares, que não se fixa nem em uma área nem em outra, que se faz construir no limiar dos conceitos. Este lugar de onde discursa Benjamin é capaz de tornar nebulosas as fronteiras entre a literatura e a filosofia; quiçá seja capaz de desvanecer a importância de tais fronteiras e de tal cisão, e é por tais razões que elegemos o seu pensamento para guiar-nos no estudo de um conceito tão caro à filosofia quanto à literatura: o tempo.

Pensando que esta instância configura um mote de amplos e variados estudos no campo da filosofia, acreditamos que ela também o faça no que diz respeito aos estudos de teoria da literatura, devido ao fato de que estamos frente a um dos pilares mais básicos da construção de uma narrativa literária. $\mathrm{O}$ ato de narrar uma história constitui, também, um ato de se localizar espacialmente em algum ponto da vastidão temporal. Intriga-nos aqui, especificamente, as narrativas que se localizam não só em algum ponto do tempo, e sim, em vários, realizando deslocamentos temporais, quebrando o fluxo linear e contínuo que, erroneamente, por vezes acredita-se ser a única forma do transcorrer do tempo.

Tornando-nos um pouco mais específicos, elencamos como objeto de nossa análise neste artigo, um dos mais - senão o mais - conhecido romance de Machado de Assis: Dom Casmurro, de 1899. Dentre as várias questões que essa clássica obra poderia suscitar, concentramo-nos aqui na forma através da qual esta narrativa realiza, justamente, os deslocamentos temporais aos quais nos referimos acima. Tratando-se de um relato ficcional de cunho primordialmente memorialista, o texto que encontramos neste romance machadiano parte de um presente melancólico em relação a um passado nostálgico e saudosista, o qual, quando contraposto ao presente em que se encontra seu narrador, revela os conflitos e as mudanças que o passar dos anos é capaz de fazer existir em um mesmo sujeito. 
A narrativa que encontramos em Dom Casmurro já foi traduzida para várias outras mídias, seja no teatro, no cinema, ou até mesmo em história em quadrinhos. Chamanos a atenção, porém, a primeira versão deste romance produzida para a televisão: a microssérie Capitu, dirigida por Luiz Fernando Carvalho em 2008. A nosso ver, essa versão traduz muitos dos aspectos concernentes à questão temporal que intriga-nos no romance Dom Casmurro.

Distanciando-nos brevemente do campo da literatura, acreditamos que um dos textos benjaminianos capazes de sintetizar de forma mais eficiente o posicionamento de tal pensador frente à instância do tempo seja, também, um de seus escritos mais conhecidos: as teses "Sobre o conceito de história", presentes em Magia e Técnica, Arte e Polítical. Escritas, segundo Jeanne Marie Gagnebin "sob o impacto do acordo de agosto de 1939 entre Stalin e Hitler" 2 tais teses desvelam a ruptura proposta por Benjamin com a noção de uma história findada e irrecuperável. Em lugar disso, será proposta a existência de múltiplas histórias, estas não delegadas a um passado ao qual não se tem mais alcance, mas sim imbuídas de uma potência capaz de fazer explodir o continuum do tempo presente.

Em Linha, Choque e Mônada - Tempo e Espaço na Obra Tardia de Walter Benjamin $^{3}$, Georg Otte discorrerá sobre a obra de Walter Benjamin a partir das categorias Tempo e Espaço, procurando mostrar como estas "não são [categorias] apenas essenciais para a 'Origem do Drama Barroco Alemão' (de 1925), ou seja, que a preocupação com elas não é apenas barroca, mas também benjaminana". ${ }^{4}$ Constatamos, portanto, que a questão do tempo é uma das principais temáticas do pensamento de Walter Benjamin. Otte afirma que tal categoria, para Benjamin, é responsável por realizar releituras críticas de conceitos como origem, progresso, tempo presente, tempo passado, entre outros. Citando:

O alvo do anarquismo benjaminiano não é simplesmente a ideologia do progresso, mas a idéia de progressão vista geralmente como qualidade indissociável do tempo. Faz parte desta ideologia a idéia de que o sujeito, enquanto gerador do progresso, ocupa um lugar exclusivo dentro da história: à maneira do observador na beira de um rio, ele assiste ao fluxo progressivo do tempo, sendo que as coisas trazidas por este fluxo aparecem e desaparecem diante dos olhos deste observador. Contrariando esta perspectiva, Benjamin não admite que o passar do tempo signifique a perda definitiva destas coisas: em primeiro lugar porque o sujeito não ocupa um lugar fixo na 'beira' da história, mas é levado por ela junto com os outros objetos; o sujeito também é objeto da história. Em segundo lugar, porque a imagem do fluxo linear, a idéia da linha do tempo em geral, é inadequada, ou pelo menos insuficiente, para uma compreensão de um presente que tem suas dívidas com o passado. ${ }^{5}$

Essa noção de tempo proposta por Walter Benjamin entra em conflito com uma noção de tempo guiada por um progresso irrefreável. Isto porque, para este pensador, o progresso não é uma instância intimamente ligada ao conceito de tempo e à qual o sujeito está imune; pelo contrário, o sujeito é, também, engolido pelo progresso, que é, por conseguinte, também catástrofe - matéria inegável do passar do tempo. Na tese de número 9, em que, através de uma alegoria, o quadro Angelus Novus de Paul Klee representa o anjo da história, lemos: 
Mas uma tempestade sopra do paraíso e prende-se em suas asas com tanta força que ele não pode mais fechá-las. Essa tempestade o impele irresistivelmente para o futuro, ao qual ele vira as costas, enquanto o amontoado de ruínas cresce até o céu. Essa tempestade é o que chamamos de progresso. ${ }^{6}$ (grifo nosso)

Para Benjamin, portanto, não é o progresso que é da ordem do tempo, e, sim, as catástrofes que se acumulam à medida que a história avança. A visão melancólica de um tempo que avança e deixa atrás de si apenas as ruínas advindas da destruição pode ser melhor compreendida se retornamos à informação inicial conferida por Gagnebin de que o contexto em que o pensador alemão escreve tais teses é um dos mais conturbados da história mundial.

O passar do tempo não poderia, retomando aqui George Otte, fazer desaparecer do olhar do sujeito o acúmulo dos acontecimentos, e este próprio sujeito nunca seria capaz de observar, simplesmente, tal acúmulo para, em seguida, esquecê-lo. É pensando, portanto, em um sujeito que não esteja à beira do fluxo desse rio da história, e, sim, dentro dessa água do tempo, que Walter Benjamin propõe uma imagem temporal que não seja representada por uma linha, mas que seja, ao invés disso, representada por uma constelação. Citando:

A verdadeira imagem do passado perpassa, veloz. O passado só se deixa fixar, como imagem que relampeja irreversivelmente, no momento em que é reconhecido. (...) Pois irrecuperável é cada imagem do presente que se dirige ao presente, sem que esse presente se sinta visado por ela. ${ }^{7}$

Para Benjamin, portanto, o passado não seria uma instância irrecuperável que tenha sido impreterivelmente levada para longe do campo de visão do sujeito pelo fluxo do tempo; ao contrário, este passado para com o qual o presente tem dívidas é, justamente, o lugar de ação do sujeito que pretende transformar a História em diversas histórias. Vale lembrar aqui, como afirma Jeanne Marie Gagnebin, na introdução de sua obra História e narração em Walter Benjamin ${ }^{8}$, que a oposição entre história e histórias não corresponde à oposição verdade e mentira, e sim à existência de várias histórias dentro de um tempo; de um "tempo saturado de agoras", 9 o Jetztzeit do qual Benjamin nos fala em sua Tese de número 12.

Retornando, agora, para o campo literário, estamos frente à história vivida por Bentinho, personagem criado sob a saia da mãe e o quintal da encantadora vizinha, que mais tarde se transformará no relato de um Dom Casmurro. É através do foco narrativo deste último que nos adentraremos pela memória e história deste personagem, sob o pretexto de unir a mocidade à velhice, de atar as pontas da vida, de repassar seu trajeto e descobrir “(...) se a Capitu da Praia da Glória já estava dentro da de Mata-Cavalos"10. Mais de um século depois do lançamento do romance de Machado de Assis, o diretor Luiz Fernando Carvalho traduz, através dos recursos de imagem-movimento, a história de Bentinho em sua microssérie Capitu, cujos cinco capítulos foram exibidos pela Rede Globo em 2008.

De quais formas, então, as obras de arte aqui elencadas relacionam-se com a noção temporal de Walter Benjamin?

A começar pelo romance machadiano, acreditamos haver ali um trânsito de temporalidades que é ativado pela chave da memória. Estamos frente a uma narrativa não-linear porque memorialista, na qual o narrador, no momento em que se 
faz escritor de seu romance fictício, propõe um pacto de volta ao passado a seu leitor. Citando:

Sim, Nero, Augusto, Massinissa e tu, grande César, que me incitas a fazer os meus comentários, agradeço-vos lhe o conselho, e vou deitar ao papel as reminiscências que me vierem vindo. Deste modo, viverei o que vivi, e assentarei a mão para obra de maior tomo. Eia, comecemos a evocação por uma célebre tarde de novembro, que nunca me esqueceu. Tive outras muitas, melhores e piores, mas aquela nunca se apagou do meu espírito. É o que vais entender, lendo. ${ }^{11}$

A oferta de Dom Casmurro a seu leitor é, portanto, uma jornada de volta a seu passado, sem itinerário muito bem definido. As reminiscências que "vierem vindo" conduzirão leitor e narrador até o terreno de sua memória, de onde serão resgatadas as lembranças que ali habitam. Acredito ser importante lembrar aqui, via Márcio Selligman-Silva, a distinção entre memória e reminiscência feita por Aristóteles em De Memória et Reminiscentia:

Aristóteles nota, no entanto, que a memória devido ao seu caráter de arquivo de imagens pertence à mesma parte da alma que a imaginação: ela é um conjunto de imagens mentais das impressões sensuais mas com um adicional temporal; trata-se de um conjunto de imagens de coisas do passado.

(...)

Aristóteles distingue de modo claro entre memória e reminiscência, como o nome do seu texto o indica. A reminiscência é definida como a recuperação intencional de um conhecimento ou de uma sensação. ${ }^{12}$

A reminiscência é, portanto, para o narrador de Dom Casmurro, a chave que dá acesso ao terreno da memória, onde se encontram os fatos, as imagens de coisas do passado que serão matéria do livro que ele busca escrever.

É, justamente, através das incursões à sua própria memória, que Dom Casmurro construirá uma narrativa na qual o tempo fictício parece próximo, de alguma forma, da noção temporal benjamiana. Ao invés de estabelecer uma narrativa cujo fluxo caminhe sempre na direção do passado para o futuro, o narrador de tal romance sai de um tempo presente para o seu passado, fazendo isso não de forma a reconstituir os fatos na ordem em que estes aconteceram, mas ao sabor das "reminiscências que vierem vindo", de acordo com um direcionamento antes afetivo que cronológico.

Entre muitos dos trechos em que isso pode ser percebido, destacamos aqui o Capítulo XLV, "Abane a cabeça, leitor", no qual o narrador interrompe o fluxo de sua narração, que se fixava no passado, e traz o leitor do meio de suas memórias diretamente para o momento da enunciação, para, então, levá-lo novamente ao passado:

Abane a cabeça, leitor; faça todos os gestos de incredulidade. Chegue a deitar fora este livro, se o tédio já não o obrigou a isso antes; tudo é possível. Mas, se o não fez antes e só agora, fio que torne a pegar do livro e que o abra na mesma página, sem crer por isso na veracidade do autor. Todavia não há nada mais exato. Foi assim mesmo que Capitu falou, com tais palavras e maneiras. Falou do primeiro filho, como se fosse a primeira boneca. ${ }^{13}$ 
O tempo que habita o romance de Machado de Assis não é, portanto, um tempo linear, que se volta ao passado como se esse fosse irrecuperável; pelo contrário, o passado torna-se matéria viva através do narrador, que ao contar sua história de forma não-linear (talvez poderíamos dizer, à maneira benjaminiana, de forma constelar) volta a apropriar-se dela e faz seu próprio passado reviver em seu presente.

Retornando novamente à teoria, sabemos que, para Benjamin, "a história é objeto de uma construção cujo lugar não é o tempo homogêneo e vazio, mas um tempo saturado de 'agoras'", ${ }^{14}$ ou seja, o tempo é uma instância de simultaneidade, e não de um encadeamento contínuo de acontecimentos que necessariamente precedem ou respondem uns aos outros. Não há, então, uma única história a se desenrolar no tempo; ao contrário, o tempo abarca múltiplas histórias. A partir disso, acreditamos que, mais uma vez, haja aspectos na narrativa de Dom Casmurro que se encontrem próximos do pensamento benjaminiano. Para esclarecer tal associação, recorremos à Helen Caldwell,crítica da obra machadiana, que, em O Otelo Brasileiro de Machado de Assis, ${ }^{15}$ a partir de uma análise postada especificamente nos aspectos inerentes ao texto machadiano, oferece-nos importantes abordagens sobre o universo ficcional no qual se engendra esse romance. Caldwell será uma das primeiras críticas a trazer para a crítica brasileira a tese de que Dom Casmurro seria, na verdade, um romance enunciado por um narrador desonesto, que advoga em defesa própria, distorcendo os fatos e criando pistas para seu leitor - este componente de um júri. A autora também compara o romance de Machado de Assis a Otelo, de William Shakespeare, percebendo em Bento Santiago a presença simultânea de um Otelo e de um Iago, que acusam uma Capitu tão inocente quanto o fora Desdêmona.

A abordagem de Caldwell elucida ao leitor de Machado de Assis outras possibilidades de leitura desse texto, ou seja, a autora traz à tona a noção de que, ainda que o narrador de Dom Casmurro tenha elegido para contar uma das histórias que transcorrem no tempo desse romance, outras histórias possíveis também estão contidas nesse universo ficcional. A famigerada dúvida que circunda essa obra também pode ser lida como uma das histórias que acontecem no tempo desse romance. Não teria Capitu outro foco narrativo frente aos acontecimentos e, portanto, outra história para narrar?

Postas tais questões referentes à aproximação entre a noção temporal de Walter Benjamin e o romance Dom Casmurro, parece-nos prudente tratar, agora, de algumas questões referentes à tradução áudio-visual de tal obra: a microssérie Capitu.

De ínicio, acreditamos que, o figurino adotado em tal microssérie seja um dos elementos com maior potencial de condensação de vários tempos distintos - de vários agoras - em si mesmo. Enquanto em Dom Casmurro - um romance, vale atentar, pouquíssimo descritivo - a vestimenta das personagens figura como caracterização, em Capitu o figurino parece trazer a microssérie para um plano temporal em que não há uma distinção linear estabelecida entre presente e passado. Em muitos momentos os personagens principais se apresentam caracterizados à moda do fim do século XIX, e contracenam com figurantes que trajam roupas comuns aos tempos atuais. A atriz que representa Capitu, Letícia Persiles, empresta à personagem sua grande tatuagem estampada em um dos braços, fazendo existir, em uma menina de séculos atrás, um adereço comum aos jovens da nossa época, fazendo o presente, de alguma forma, habitar o passado, e vice-versa. 
A cenografia da série também é responsável, em alguns momentos, por reunir em si elementos do passado e do presente. Gravada, em grande parte, no Automóvel Clube do Brasil, no Rio de Janeiro, a microssérie conta com um cenário que, por vezes, é teatral e, por vezes, apresenta o mínimo possível de caracterização (como é o caso do quintal da casa de Capitu, representado por desenhos riscados de giz no chão), o que, talvez, poderia ser interpretado como uma tentativa de tradução da narrativa pouco descritiva, empregada por Machado de Assis em seu romance. É nesse cenário que o personagem-narrador irá contar sua história - em um tempo que seria o do enunciado - e, simultaneamente, observá-la acontecer diante de seus olhos. Luiz Fernando Carvalho, enquanto tradutor, parece conferir a Dom Casmurro algo que vai além de sua capacidade narrativa - o que é observado no romance de Machado de Assis -; o diretor personifica o narrador, colocando-o não só como aquele que rememora seu passado, mas também como espectador de seu próprio passado, para o qual uma incursão física ao terreno da memória é possível. Além disso, em alguns momentos observamos imagens atuais da cidade do Rio de Janeiro contrastando com a ambientação antiga proposta pela microssérie. Em um trecho do primeiro episódio, por exemplo, o narrador Casmurro circula pela cidade dentro de um metrô.

Outro elemento cuja função dentro desse processo de tradução parece-nos passível de análise é a trilha sonora. Predominantemente elaborada por músicas compostas entre a segunda metade do século XX e os tempos atuais, a trilha sonora não só confere significado e caracteriza os personagens como os transporta diretamente do passado para o presente, trazendo, assim, as figuras machadianas para um tempo que contém em si vários outros tempos, como propõe Walter Benjamin.

Por fim, retornamos, mais uma vez, a Benjamin, em seu ensaio de título "A Imagem de Proust", onde lemos: "pois um acontecimento vivido é finito, ou pelo menos encerrado na esfera do vivido, ao passo que o acontecimento lembrado é sem limites, porque é apenas uma chave para tudo que veio antes e depois."16

Ainda que a este ponto o pensador alemão esteja discorrendo sobre a obra de Marcel Proust, acreditamos que o seu pensamento acerca da memória e da questão temporal não se restrinja ao escritor francês, e encontre ecos, também, na obra de Machado de Assis. Isto porque é, justamente, através dos recursos rememorativos, ou seja, dos atos de lembrar, que o narrador de Dom Casmurro reconstituirá sua história passada e constituirá sua futura história. A memória funciona aqui exatamente como a chave que permite acesso ao campo do que fora vivido, conferindo àquele que rememora a chance de pinçar, no fluxo do tempo, dentre tantas outras histórias, a história que ele elegeu como sua. Enquanto romancista solitário, ao qual Benjamin alude em "O Narrador", o próprio personagem-narrador de Dom Casmurro revive e recria a perplexidade do que experienciou ${ }^{17}$, através do advento da memória.

Abstract: The following article intends to relate Walter Benjamin's conception of time - especifically as it appears in On the Concept of History - to the novel Dom Casmurro, by Machado de Assis, and its television adapation, the microseries Capitu, directed by Luiz Fernando Carvalho. We intend to understand, specifically, in which manners the time 
that runs through both of these works is close to Benjamin's image of a constelatte, multiple, nonlinear and heterogeneous time.

Keywords: time; memory; intersemiotic translation.

\section{Referências Bibliográficas}

ASSIS, Machado de. Dom Casmurro. 2a ed. Porto Alegre: L\&PM, 2008. p. 47-247.

BENJAMIN, Walter. Obras escolhidas volume 1: Magia e técnica, arte e política: Ensaios sobre a literatura e história da cultura. $7^{\mathrm{a}}$ ed. Trad. Sérgio Paulo Rouanet. São Paulo: Brasiliense, 1994. p. 7-253.

CALDWELL, Helen. O Otelo Brasileiro de Machado de Assis. $2^{\mathrm{a}}$ ed. Trad. Fábio Fonseca de Melo. Cotia: Ateliê Editorial, 2002. p. 224.

GAGNEBIN, Jeanne Marie. História e Narração em Walter Benjamin. $2^{\mathrm{a}}$ ed. São Paulo: Editora Perspectiva, 1999. p. 5-128.

LÖWY, Michael. Walter Benjamin: aviso de incêndio: uma leitura das teses sobre o conceito de história. Trad. Wanda Nogueira Caldeira Brant. São Paulo: Boitempo, 2005. p. 6-160.

OTTE, Georg. Linha, Choque e Mônada: Tempo e espaço na obra tardia de Walter Benjamin. Belo Horizonte: UFMG, 1994. p. 5-276.

SELIGMANN-SILVA, Márcio. A escritura da memória: mostrar palavras e narrar imagens. Terceira Margem: Revista do Programa de Pós Graduação em Ciência da Literatura. Rio de Janeiro: UFRJ, p. 91-107, 2002.

\section{Notas}

1 “(...) esta homonímia, à qual estamos acostumados, nos indica uma comunidade de significação mais forte que a oposição habitual entre 'histórias' (plural) que deveriam se contadas para desviar dos fatos e a 'história' (singular) que deveria nos restituir a verdade do passado." (GAGNEBIN. História e Narração em Walter Benjamin. p. 2)

${ }^{1}$ BENJAMIN. Magia e Técnica, Arte e Política.

${ }^{2}$ GAGNEBIN apud BENJAMIN. Magia e Técnica, Arte e Política, p. 8.

${ }^{3}$ OTTE. Linha, Choque e Mônada.

${ }^{4}$ OTTE. Linha, Choque e Mônada, p. 6.

${ }^{5}$ OTTE. Linha, Choque e Mônada p. 8.

${ }^{6}$ BENJAMIN. Magia e Técnica, Arte e Política p. 226.

${ }^{7}$ BENJAMIN. Magia e Técnica, Arte e Política, p. 224.

${ }^{8}$ GAGBEBIN. História e Narração em Walter Benjamin, 2011.

${ }^{9}$ BENJAMIN. Magia e Técnica, Arte e Política, p. 228.

${ }^{10}$ ASSIS. Dom Casmurro.

${ }^{11}$ ASSIS. Dom Casmurro, p. 53. 
${ }^{12}$ SELIGMANN-SILVA. A escritura da memória: mostrar palavras e narrar imagens, p.93-94.

${ }^{13}$ ASSIS. Dom Casmurro, p. 120.

${ }^{14}$ BENJAMIN. Magia e Técnica, Arte e Política, p. 229.

${ }^{15}$ CALDWELL. O Otelo Brasileiro de Machado de Assis.

${ }^{16}$ BENJAMIN. Magia e Técnica, Arte e Política, p. 37.

${ }^{17}$ BENJAMIN. Magia e Técnica, Arte e Política, p. 201. 